\title{
Electrochemical Polymerization of Aniline on Aluminum Electrode from an Oxalic Acid and $\mathrm{H}_{2} \mathrm{SO}_{4}$ Solutions ${ }^{1}$
}

\author{
A. Buyuksagis \\ Afyon Kocatepe University Science and Art Faculty, Afyonkarahisar, TURKEY \\ e-mail:absagis@aku.edu.tr,ayselbuyuksagis@hotmail.com \\ Received January 11, 2008
}

\begin{abstract}
In this study, the polymerization of aniline on Al and Pt electrode was examined by cyclic voltammetry There had been reversible reaction on AI electrode. But on the other hand there had been irreversible reaction on Pt electrode. The addition of aniline into the solution led the decrease of current values. The current decreased by adsorption of anodic products on polymer surface. The fact that the anodic peak potential shifted to positive value shows that polyaniline (PANI) catalyzed the formation of polymer. This case shows that the aniline shifted the electrode potential to positive side by the adsorption on the surface. When Al electrode covered with polymer (in $50 \mathrm{mV} \mathrm{s}^{-1}$ potential scanning rate after 20 cycles) was immersed into $1 \mathrm{~N} \mathrm{HCl} \mathrm{solution}$, the inorganic layer decomposed on the metal surface. This led to decrease the polarization resistance of the metal. SEM microphotographs and EDX fingerprints also confirmed these results.
\end{abstract}

PACS numbers: @@@@

DOI: $10.1134 / \mathrm{S} 2070205109050220$

\section{INTRODUCTION}

There are, also, a number of reports in the literature in which polyaniline has been deposited at aluminum or aluminum alloys [1, 2]. Furthermore, the electrodeposition of PANI on an active metal is likely to be affected by corrosion or passivation of the electrode in strongly acidic polymerization media. For example, Abalayev and Efimov (1997) used transition metal ions as catalysts for electrodeposition of PANI on an Al electrode. Racicot et al. (1997) studied the corrosion resistance of chemically synthesized PANI coating on aluminum alloy 7075-T6 in $0.5 \mathrm{M} \mathrm{NaCl}$ solution. They concluded that the corrosion current density for the metal sample coated with conductive PANI was two orders of magnitude lower than that for the uncoated sample and one order of magnitude lower than for the sample coated with non-conductive PANI. For example, Epstein et al. (1999) have studied the corrosion protection properties of polyaniline in the emeraldine base form and selfdoped sulfonated polyaniline cast-deposited at Al 3003 and Al2024-T3 alloys. They found that these coatings were effective in reducing the corrosion rate when the coated electrodes were exposed to chloride environments. They also proposed that the polyaniline coatings facilitated the extraction of copper from the surface of the $\mathrm{Al}$ 2024-T3 alloy, thereby reducing the galvanic couple between aluminum and copper and reducing the corrosion rate. Racicot et al. (1997) have also reported the corrosion protection of aluminum alloys using a

\footnotetext{
${ }^{1}$ The article is published in the original.
}

double-stranded polyaniline coating. They concluded that the conducting polymer was not a barrier coating, but that it converted the surface of the alloy to an oxidized state to form a passive layer that facilitated corrosion protection. The objective of this work is to investigate aniline oxidation on aluminum and platinum electrode in order to determine the electrochemical conditions that allow the growth of PANI films with properties similar to those obtained in aqueous acids.

\section{EXPERIMENTAL DETAILS}

Test specimens were prepared from pure aluminum rod samples. The electrode was embedded in epoxy resin in a teflon holder and electrical contact achieved by means of a wire threaded into the base of the metal sample. The exposed surfaces were polished to a 1200 grit using $\mathrm{SiC}$ paper. They were then cleaned in bidis- 2 tilled water. The electrochemical cell consists of a three-electrode cell. A saturated calomel electrode (SCE) was used as the reference electrode and a Pt wire were used as the auxiliary electrodes. All potentials are measured of the SCE scale. After mechanically polishing with emery paper (1200 grades), the surface was cleaned in ethanol/acetone. All test solutions were prepared from Merck grade reagents and bidistilled water. 2 Aniline was purified by distillation and stored in the absence of light. The solutions were prepared by diluted oxalic acid in bidistilled water and then slowly 2 adding the aniline. All studies were done at room temperature. Electrochemical experiments were carried out 
(a)

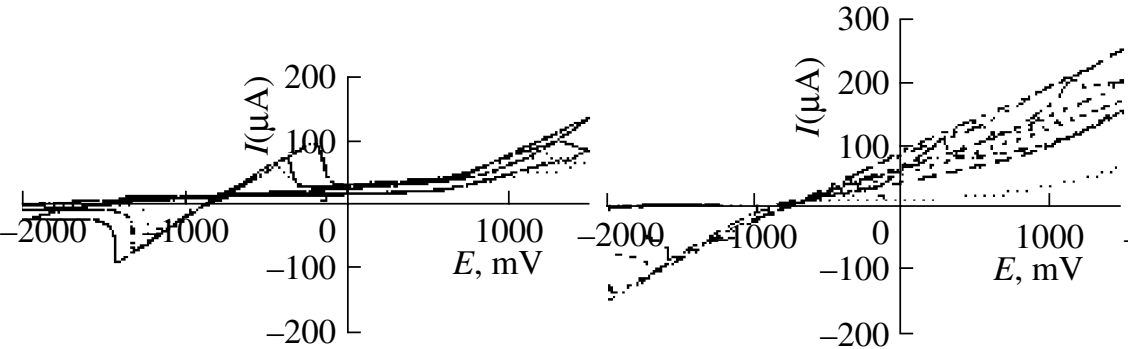

(d)

(e)

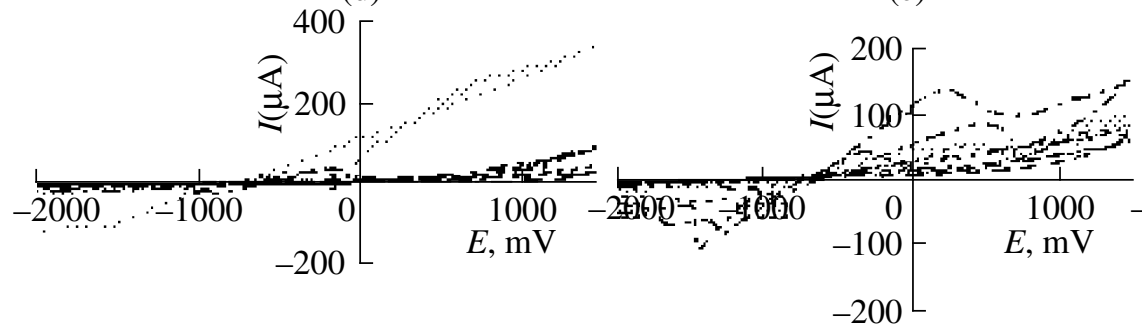

(c)

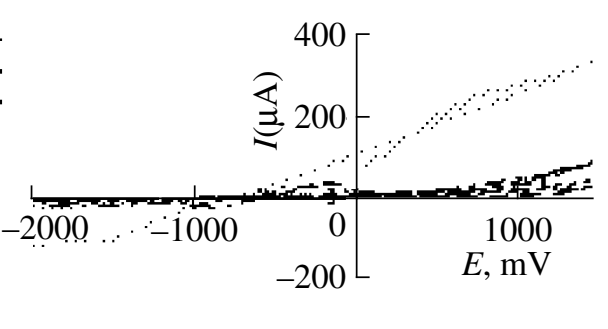

(f)

Fig. 1. Effects of sweep rate on $\mathrm{Al}$ electrode (a) $1 \mathrm{~N} \mathrm{H}_{2} \mathrm{SO}_{4}$, (b) $1 \mathrm{~N} \mathrm{H}_{2} \mathrm{SO}_{4}+0.1 \mathrm{M}$ aniline, (c) $0.3 \mathrm{M}$ oxalic acid, (d) $0.3 \mathrm{M}$ oxalic acid $+0.1 \mathrm{M}$ aniline, (e) $1 \mathrm{~N} \mathrm{H}_{2} \mathrm{SO}_{4}+0.3 \mathrm{M}$ oxalic acid, (f) $1 \mathrm{~N} \mathrm{H}_{2} \mathrm{SO}_{4}+0.3 \mathrm{M}$ oxalic acid $+0.1 \mathrm{M}$ aniline $\left(\ldots \ldots \ldots .5 \mathrm{mV} \mathrm{s}{ }^{-1}\right.$, - - - $\left.10 \mathrm{mV} \mathrm{s}^{-1},-----20 \mathrm{mV} \mathrm{s}^{-1}, 50 \mathrm{mV} \mathrm{s}^{-1},-. . .-100 \mathrm{mV} \mathrm{s}^{-1}\right)$.

using an Wenking Model Potentiostat, connected to a personal computer through a USB electrochemical interface. Cyclic voltammetry measurements were performed in the monomer- free solutions and containing monomer solutions at scan rates of 5, 10, 20, 50 and $100 \mathrm{mV} \mathrm{s}^{-1}$. Electropolymerization of aniline on the bare $\mathrm{Al}$ and $\mathrm{Pt}$ electrodes was performed by a potentiodynamic method with a scan rate of $50 \mathrm{mV} \mathrm{s}^{-1}$ between -2 and $1.5 \mathrm{~V}$ in $0.3 \mathrm{M}$ oxalic acid $+0.1 \mathrm{M}$ aniline, $1 \mathrm{~N}$ $\mathrm{H}_{2} \mathrm{SO}_{4}+0.1 \mathrm{M}$ aniline and $1 \mathrm{~N} \mathrm{H}_{2} \mathrm{SO}_{4}+0.3 \mathrm{M}$ oxalic acid $+0.1 \mathrm{M}$ aniline solutions. PANI was deposited on $\mathrm{Al}$ and Pt electrodes in order to determine electrochemical characterization. This process was performed by 20 cycles. Once the polymers on the Al electrode 2 formed, the electrode surface was rinsed with bidistilled water and then the electrode was immersed in the $1 \mathrm{~N} \mathrm{HCl}$. Chloride-containing solutions were employed to study the corrosion-protection properties of the polymer coatings. Anodic polarization tests were performed by polarizing the electrodes starting from the corrosion potential at a scan rate of $2.0 \mathrm{mV} \mathrm{s}^{-1}$ in the anodic direction. The morphology of the PANI on the Al electrodes were investigated with a scanning electron microscope. SEM-EDX specimens were prepared by using electropolymerization of aniline on the electrode substrates. After that exposed surface of electrode was cut in about $2 \mathrm{~mm}$.

\section{RESULTS AND DISCUSSIONS}

When the 20 cyclic curves in all solutions are examined for platinum and aluminum (Figs. 2-4), the reduc- tion potential in $\mathrm{Al}$ is much more negative potentials about $1000 \mathrm{mV}$ and the reduction of peak current is much bigger than for platinum. The same case is valid for the oxidation peak potentials and oxidation peak currents. When the scan rate in aluminum and platinum rises (Figs. 1-3), reduction peak potentials have shifted to more negative potentials and the currents have increased. On the other hand oxidation peak potentials have shifted to more positive values and the peak currents have increased $[1,7,9]$.

When the 20 cycles voltamograms (Figs. 1c, 1d, 1e) in oxalic acid solutions are examined, there are both reduction and oxidation peak on $\mathrm{Al}$ and also there is an reversible reaction on it. On the other hand there is only one reduction peak on platinum (Figs. 4c, 4d) and there is also an irreversible reaction on it $[10,11]$. When the voltamograms (Figs. 1c, 1d), obtained for platinum in $0.3 \mathrm{M}$ oxalic and $0.3 \mathrm{M}$ oxalic acid $+0.1 \mathrm{~N}$ aniline solutions, are examined, it can be said that the current passing in a highly extensive potential range is very low, almost nearly zero. The fact the rising of the current after $0.8 \mathrm{~V}$ shows the oxygen exit. The reaction below has occurred because of acidic solution $[9,12]$;

$$
2 \mathrm{H}_{2} \mathrm{O}(\mathrm{aq}) \longrightarrow \mathrm{O}_{2}(\mathrm{~g})+4 \mathrm{H}^{+}+4 \text { é. }
$$

The addition of aniline into $0,3 \mathrm{M}$ oxalic acidic solution (Fig. 2d) makes the current values on Al minimized. While the reduction peak potentials have been shifted to more negative values, oxidation peak potentials have been shifted to more positive potentials. The fact the decreasing of the current values shows that the oxalic acid has closed the polymer layer or the current 
(a)

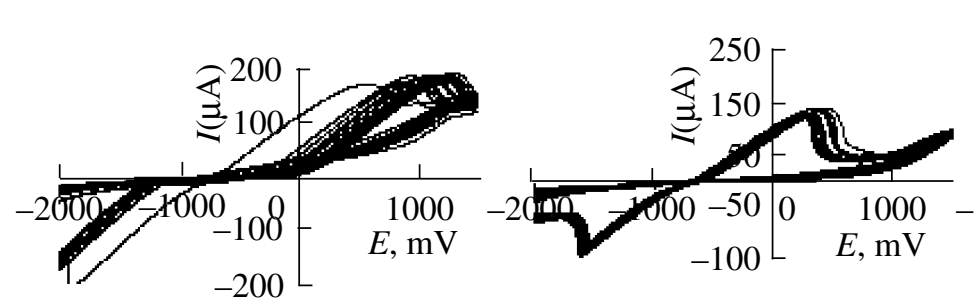

(d) (b)

(e) (c)

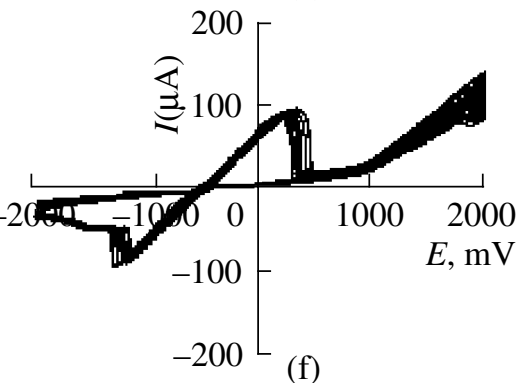

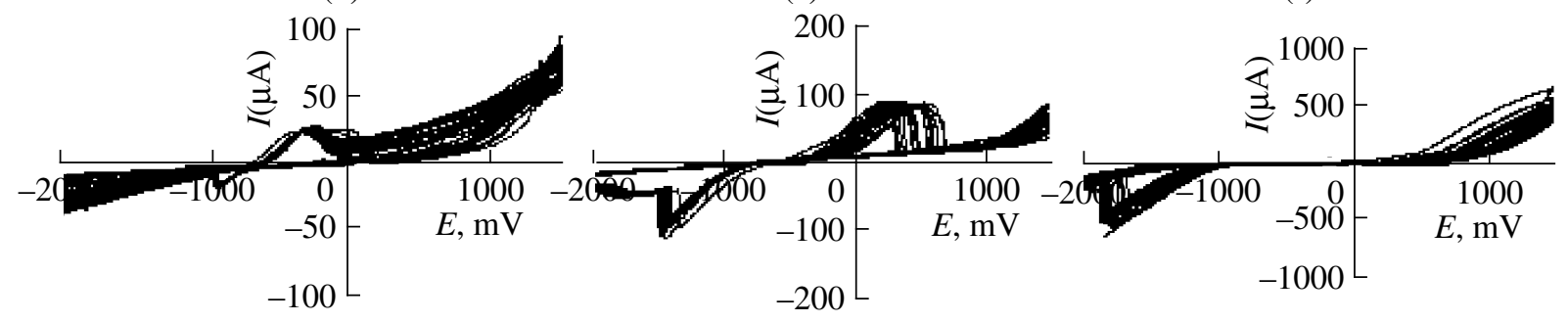

Fig. 2. The voltammograms recorded for $\mathrm{Al}$ electrode, scan rate: $50 \mathrm{mV} \mathrm{s}^{-1}$. (a) $1 \mathrm{~N} \mathrm{H}_{2} \mathrm{SO}_{4}$, (b) $1 \mathrm{~N} \mathrm{H}_{2} \mathrm{SO}_{4}+0.1 \mathrm{M}$ aniline, (c) $0.3 \mathrm{M}$ oxalic acid, (d) $0.3 \mathrm{M}$ oxalic acid $+0.1 \mathrm{M}$ aniline, (e) $1 \mathrm{~N} \mathrm{H}_{2} \mathrm{SO}_{4}+0.3 \mathrm{M}$ oxalic acid, (f) $1 \mathrm{~N} \mathrm{H}_{2} \mathrm{SO}_{4}+0.3 \mathrm{M}$ oxalic acid $+0.1 \mathrm{M}$ aniline.

(a)

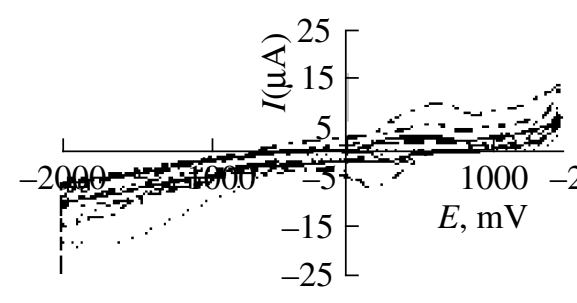

(d) (b)

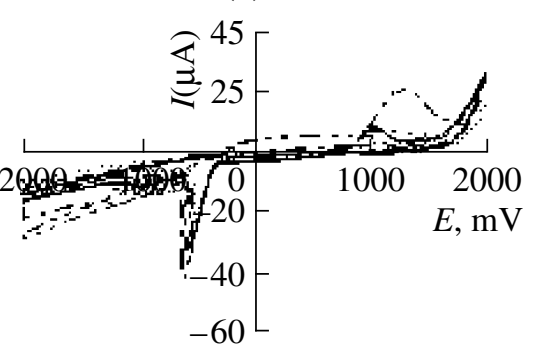

(e) (c)

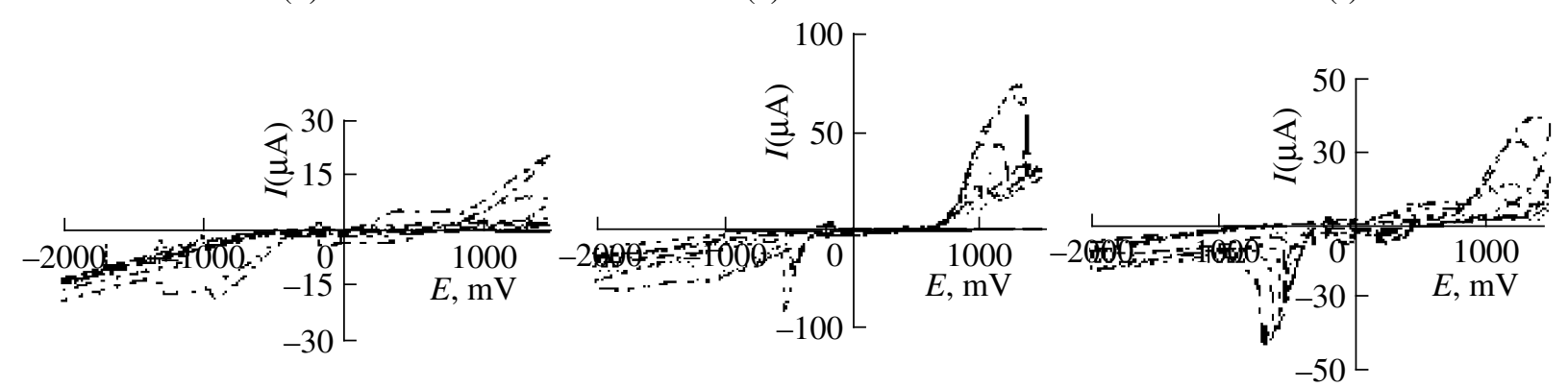

Fig. 3. Effects of sweep rate on Pt electrode (a) $1 \mathrm{~N} \mathrm{H}_{2} \mathrm{SO}_{4}$, (b) $1 \mathrm{~N} \mathrm{H}_{2} \mathrm{SO}_{4}+0.1 \mathrm{M}$ aniline, (c) $0.3 \mathrm{M}$ oxalic acid, (d) $0.3 \mathrm{M}$ oxalic acid $+0.1 \mathrm{M}$ aniline, (e) $1 \mathrm{~N} \mathrm{H}_{2} \mathrm{SO}_{4}+0.3 \mathrm{M}$ oxalic acid, (f) $1 \mathrm{~N} \mathrm{H}_{2} \mathrm{SO}_{4}+0.3 \mathrm{M}$ oxalic acid $+0.1 \mathrm{M}$ aniline $\left(\ldots \ldots \ldots 5 \mathrm{mV} \mathrm{s}{ }^{-1}\right.$, - - - $\left.10 \mathrm{mV} \mathrm{s}^{-1},----20 \mathrm{mV} \mathrm{s}^{-1}, 50 \mathrm{mV} \mathrm{s}^{-1},-. .-.-100 \mathrm{mV} \mathrm{s}^{-1}\right)$.

has decreased as a result of adsorption of oxidation products on polymer surface. Also the fact that oxidation peak potential has shifted to positive values indicates that polyaniline (PANI) has catalyzed the occurrence of polymer. And also the increasing of cycle number and current values reveal that the occurred polymer film has grown up regularly. Although the oxidation peak potential for $\mathrm{Al}$ is high, there is no range of passiveness or range of it is very narrow. On the other hand there is a range of passiveness on $\mathrm{Pt}$ generally (Figs. 4c, $4 \mathrm{~d}, 4 \mathrm{e})$ During the subsequent scans, the oxidation of aniline occurs at lower potentials due to the catalytic effect of PANI, which results in a growth of the deposited $[7,10,13]$. 
(a)

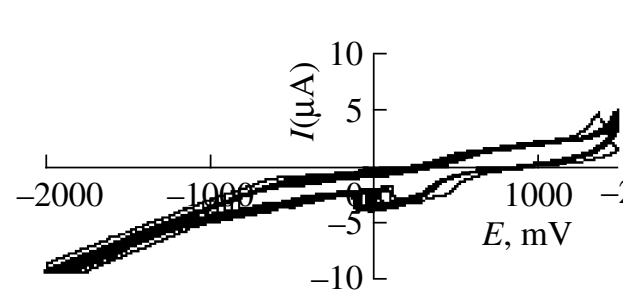

(d)

(i) (b) (c)

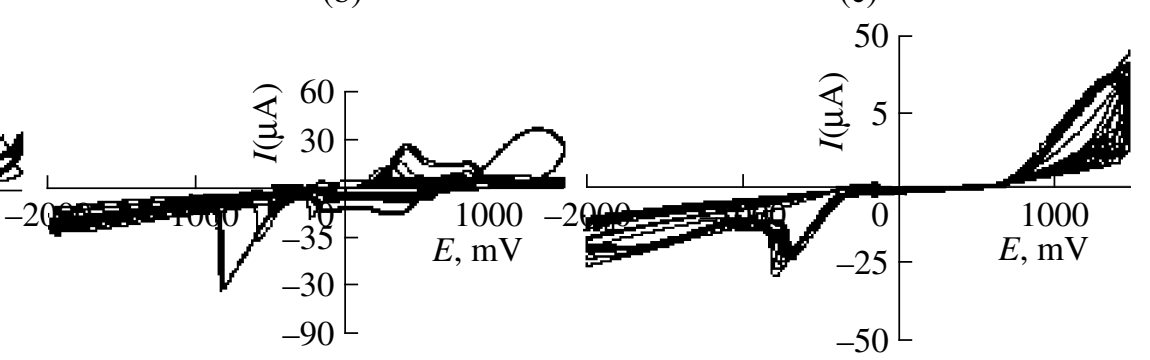

(e)

(f)

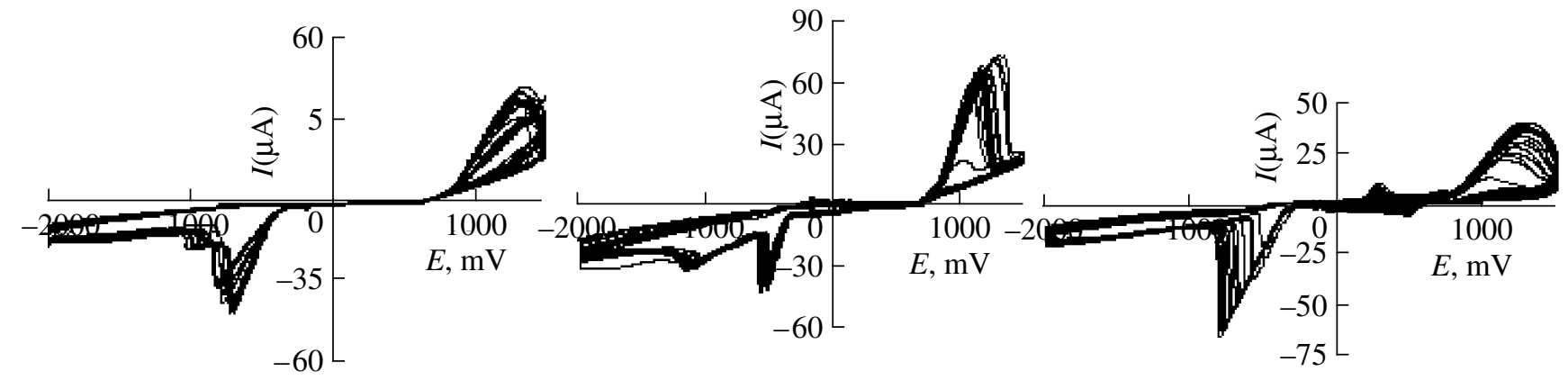

Fig. 4. The voltammograms recorded for Pt electrode, scan rate: $50 \mathrm{mV} \mathrm{s}^{-1}$. (a) $1 \mathrm{~N} \mathrm{H}_{2} \mathrm{SO}_{4}$, (b) $1 \mathrm{~N} \mathrm{H}_{2} \mathrm{SO}_{4}+0.1 \mathrm{M}^{2}$ aniline, (c) $0.3 \mathrm{M}$ oxalic acid, (d) $0.3 \mathrm{M}$ oxalic acid $+0.1 \mathrm{M}$ aniline, (e) $1 \mathrm{~N} \mathrm{H}_{2} \mathrm{SO}_{4}+0.3 \mathrm{M}_{\text {oxalic }}$ acid, (f) $1 \mathrm{~N} \mathrm{H}_{2} \mathrm{SO}_{4}+0.3 \mathrm{M}$ oxalic acid + $0.1 \mathrm{M}$ aniline.

When 20 cycles for $\mathrm{Al}$ in $1 \mathrm{~N} \mathrm{H}_{2} \mathrm{SO}_{4}$ solution (Fig. 2a) are examined, oxidation and reduction peak currents have occurred at more positive and more negative potentials respectively compared with $1 \mathrm{~N} \mathrm{H}_{2} \mathrm{SO}_{4}+0.1 \mathrm{~N}$ aniline solution (Fig. 2b). When 20 cycles for Pt in $1 \mathrm{~N} \mathrm{H}_{2} \mathrm{SO}_{4}$ solution are examined (Fig. 4a), nearly $0 \mathrm{~V}$ hydrogen desorption oxidation peak, nearly $0.5 \mathrm{~V}$. Pt-OH/Pt-O formation and the exit of $\mathrm{O}_{2}$ after $1.2 \mathrm{~V}$ can be seen easily. Furthermore, nearly $0.045 \mathrm{~V}$ hydrogen adsorption reduction peak can be seen on the background cyclic. It is claimed that anodic oxidation on aniline Pt electrode has progressed with free radical mechanism in sulphuric acid solution and it is also claimed that the last production occurred finally is octamer emeraldyn. This mechanism has been suggested according to measuring of kinetic parameters on the stage of load transfer at the first [14].

The aniline on Pt surface got oxidized at the first cycling (Fig. 2b) as a result of the addition of aniline into $1 \mathrm{~N} \mathrm{H}_{2} \mathrm{SO}_{4}$ solution. Aniline oxidation became much lower potentials at the following scans. While the electrode surface has been covered with polymer film, the peaks belonging to the occurred polymer has been clarified easily. On the other hand, increasing number of cycling and the change in the peak potentials are not important. The increasing of peak currents on the electro polymerization process indicates the development rate of polymer. The development of polymer is accorded with the increasing number of cycling and increasing of the current $[1,7,10,13]$.
Comparison of the voltamograms of PANI film growth on the Al electrode and Pt electrode (Figs. 1-4) shows that the current of all peaks is lower in the case of bare $\mathrm{Al}$ electrode than the Pt electrode. This suggests that the initial oxidation of aniline and growth rate of polyaniline on a Pt electrode is more favorable than $\mathrm{Al}$ electrode. $\mathrm{Al}$ is an active metal. The main problem connected with active metals as substrates arises from the fact that due to oxidation polarization of electrode, two simultaneous processes proceed on the anode; electrodeposition of the polymer layer and dissolution of the support metal (or its passivity). If the later process is faster, polymer film cannot be formed on the electrode surface. Such a situation after takes place when the polymer is a electrodeposited from an aqueous solution. Conducting polymers, such as polyaniline, are electrosynthesized easily at inert electrodes such as gold and platinum, but it is much more difficult to generate these polymers at aluminum electrodes. This is connected with the thin, but highly stable protective oxide, $\mathrm{Al}_{2} \mathrm{O}_{3}$, which forms on aluminum, and acts as a barrier inhibiting electron transfer and the polymerization process. Furthermore, this oxide grows through an anodization process in the acidic solutions normally employed in the electrosynthesis of conducting polymers. It is commonly accepted that oxidation of aluminum occurs in acidic media to generate the well-known duplex structure, with an inner barrier layer and outer porous layer [1, 11, 13, 15-17]. 
During the first scan the aluminum surface is covered by an oxide layer which protects the electrode against more corrosion. It also should be noted that alter this step, no oxidation peak is observed even at more acidic media. If the passive layer is formed on the electrode surface, it will protect the $\mathrm{Al}$ electrode from the dissolution and further progress of the above-mentioned reactions. The aluminum electrode covered by the aluminum oxide film has interesting electrochemical properties as the oxidation aluminum oxide formed on the electrode surface is an ionic conductor in electrolytic solutions. Thus the aluminum vacancies and oxygen vacancies act as the charge carrier, in the film. On the other hand, the movement of point's defects through the oxidation oxide film on the aluminum electrode contributes the formation of the film $[1,10-12,18]$.

This could be the proton reduction limited by the diffusion of protons inside the polymer, or the polyaniline reduction limited by the diffusion of anions inside the polymer.

The first cycle for $\mathrm{Al}$ (Figs. 1, 2) shows aniline oxidation starting around $0.5 \mathrm{~V}$ and in the following cycles a positive shift of the aniline oxidation peak associated with a strong intensity decrease is observed. This indicates that some material has deposited on the electrode. The reduction peak on $\mathrm{Al}$ has shifted to more positive potentials because of addition of oxalic acid into $\mathrm{H}_{2} \mathrm{SO}_{4}$. The current values have decreased in the solution compared to that of $\mathrm{H}_{2} \mathrm{SO}_{4}$. But on the other hand it has increased in the solution compared to that of oxalic acid. There has been no remarkable change in oxidation peak. The addition of oxalic acid has made $\mathrm{Al}$ passive, which has led to a passiveness range. Generally, when the all solutions composed of oxalic acid are examined, all of them have got passiveness range. However, there has been observed no passiveness range in $\mathrm{H}_{2} \mathrm{SO}_{4}$ solutions. It can be mentioned the second oxidation and reduction peaks in the solutions composed of $\mathrm{H}_{2} \mathrm{SO}_{4}$. And this has resulted from the ionization of $\mathrm{H}_{2} \mathrm{SO}_{4}$ like that [9];

$$
\begin{aligned}
\mathrm{H}_{2} \mathrm{SO}_{4} \longrightarrow \mathrm{H}^{+}+\mathrm{H}_{2} \mathrm{SO}_{4}^{-}, \\
\mathrm{HSO}_{4}^{-} \longrightarrow \mathrm{H}^{+}+\mathrm{SO}_{4}^{2-} .
\end{aligned}
$$

And it has also resulted from that they have got different ionization potentials.

The oxidation and the reduction current peak potentials (Fig. 1) has shifted to positive values depending on scanning rate in the solution composed of aniline and as a result of this the current values have increased. However the addition of oxalic acid into the solution has led decreasing of current values. The fact that the oxidation peaks have shifted to positive values shows that the aniline adsorbed on the surface has shifted the electrode potential to positive side. The most important result of
$\mathrm{Rp}$ values of $\mathrm{Al}$ electrode, different waited hours in $1 \mathrm{~N} \mathrm{HCl}$ (after 20 cycles, scan rate: $50 \mathrm{mV} / \mathrm{s}$ )

\begin{tabular}{l|r|r|r|r}
\hline \multirow{2}{*}{\multicolumn{1}{c|}{ Medium }} & \multicolumn{4}{|c}{$\mathrm{R}_{\mathrm{p}}, \Omega \mathrm{cm}^{2}$} \\
\cline { 2 - 5 } & 1 hour & 2 hours & 3 hours & 4 hours \\
\hline $\mathrm{HCl}$ (no 20 cycles) & 205.1 & 99.2 & 76.7 & 39.0 \\
$1 \mathrm{~N} \mathrm{H}_{2} \mathrm{SO}_{4}$ & 59.9 & 61.5 & 123.2 & 144.7 \\
$1 \mathrm{~N} \mathrm{H}_{2} \mathrm{SO}_{4}+0.1 \mathrm{M}$ & 53.8 & 46.6 & 42.1 & 38.7 \\
aniline & & & & \\
$0.3 \mathrm{M} \mathrm{oxalic} \mathrm{acid}_{1 \mathrm{~N} \mathrm{H}_{2} \mathrm{SO}_{4}+0.3 \mathrm{M}}$ & 218.8 & 115.2 & 60.6 & 48.6 \\
oxalic acid & 281 & 215.4 & 43.9 & 35.1 \\
\hline
\end{tabular}

corrosion protection of aluminum by PANI is that their potential shifts to noble values. In comparison to $E_{\text {cor }}$ of the bare steel, the more positive value, the more noble material. This potential shifts are regarded as the anodic protection potential. It seems that chemically prepared PANI coatings shift the potential to more noble values than the electrochemically prepared ones. The reason for this behavior needs to be clarified, however, it is expected that the electrochemical polymerization (electric current circulating on the surface) will promote a change on the metallic surface, which contributes to the less noble behavior $[9,11]$.

Due to the fact that the addition of oxalic acid into $1 \mathrm{~N} \mathrm{H}_{2} \mathrm{SO}_{4}+0.1 \mathrm{M}$ aniline solution gets the polymerization probably faster, the formed oxidation product has closed the surface and the cathodic peak potential has shifted to $-1900 \mathrm{mV}$ and the current value is $-623 \mathrm{~mA}$.

When the $\mathrm{Al}$ electrode covered with polymer in $50 \mathrm{mV} \mathrm{s}^{-1}$ potential scanning rate and 20 cycles is immersed $1 \mathrm{~N} \mathrm{HCl}$ solution, the inorganic layer on the metal surface is probably decomposed. This leads to decrease the polarization resistance of the metal. However, as aluminum electrode covered with polymer is stored in $1 \mathrm{~N} \mathrm{H}_{2} \mathrm{SO}_{4}$, the polarization resistance decreases. Having plunged into $1 \mathrm{~N} \mathrm{H}_{2} \mathrm{SO}_{4}+0.3 \mathrm{M}$ oxalic acid and $1 \mathrm{~N} \mathrm{H}_{2} \mathrm{SO}_{4}+0.3 \mathrm{M}$ oxalic acid $+0.1 \mathrm{M}$ aniline solution, the measured polarization resistance has decreased in the course of time. This case has confirmed the proposed thesis. As the storing period increases, the polarization resistance decreases. This case has likely resulted from the decomposition of the inorganic materials that close the surface. As the storing period increases, the inorganic material decomposes and the resistance approaches to polymer resistance (table). SEM microphotographs and EDX fingerprints have also confirmed these results (Figs. 5, 6). 

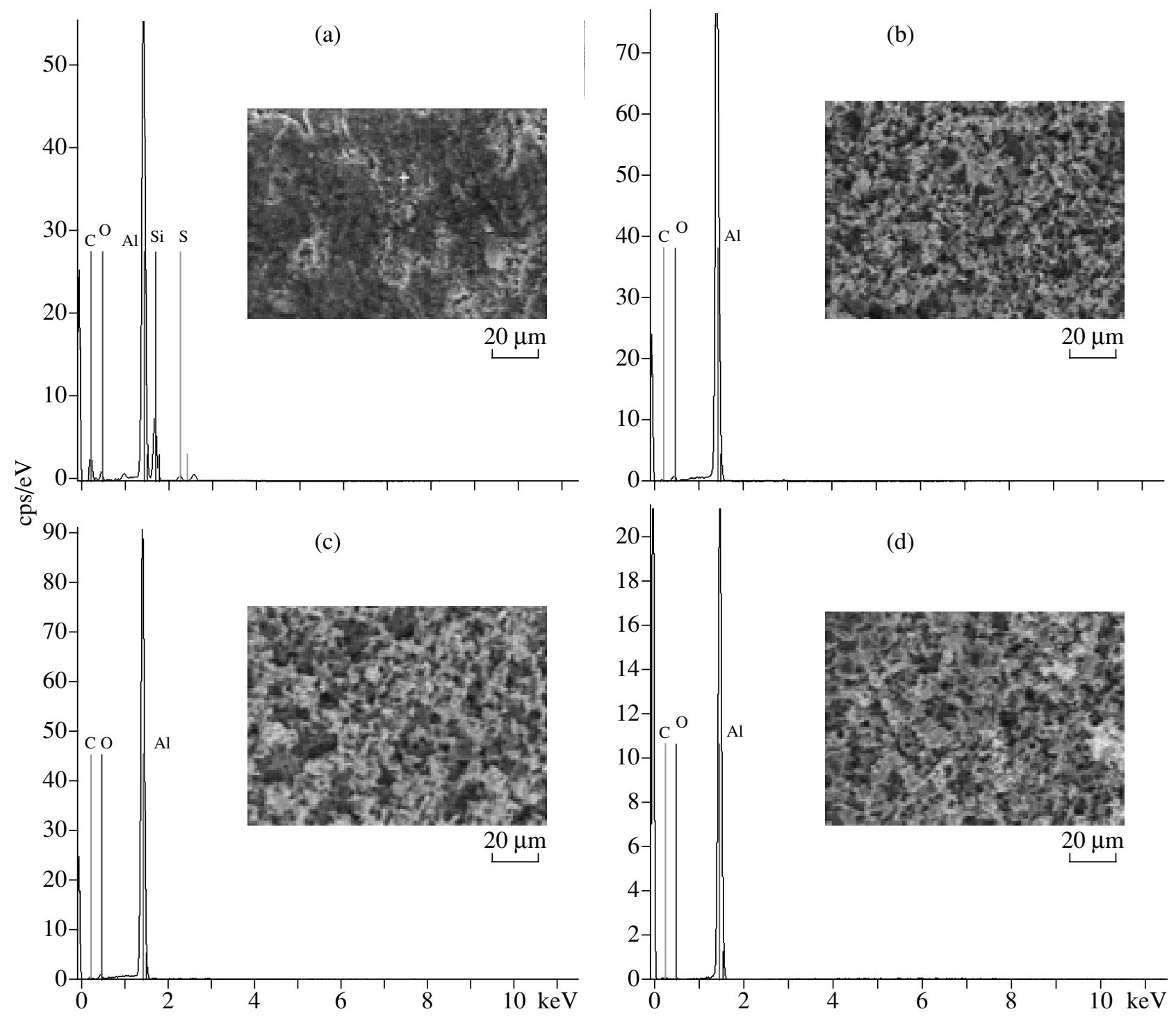

Fig. 5. Waited 4 hours $1 \mathrm{~N} \mathrm{HCl}$ for $\mathrm{Al} \mathrm{EDX}$, after 20 cycles in (a) $1 \mathrm{~N} \mathrm{H}_{2} \mathrm{SO}_{4}+0.1 \mathrm{M}$ aniline, (b) $0.3 \mathrm{M}$ oxalic acid $+0.1 \mathrm{M}$ aniline, (c) $1 \mathrm{~N} \mathrm{H}_{2} \mathrm{SO}_{4}+0.3 \mathrm{M}$ oxalic acid $+0.1 \mathrm{M}$ aniline, (d) $1 \mathrm{~N} \mathrm{H}_{2} \mathrm{SO}_{4}+0.3 \mathrm{M}$ oxalic acid.
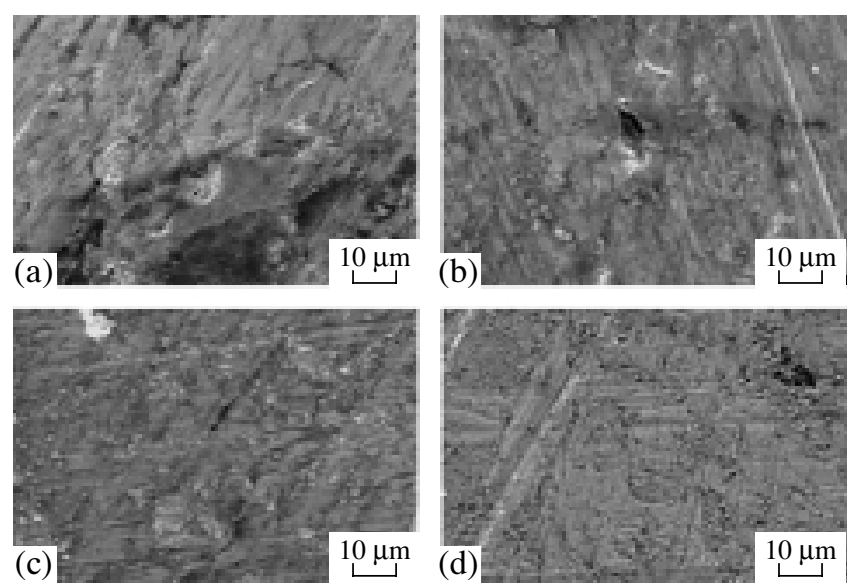

Fig. 6. SEM images after 20 cycles for $\mathrm{Al}$, scan rate: $50 \mathrm{mV} / \mathrm{s}$, (A) $0.3 \mathrm{M}$ oxalic acid $+0.1 \mathrm{M}$ aniline, (B) $1 \mathrm{~N} \mathrm{H}_{2} \mathrm{SO}_{4}$ $+0.1 \mathrm{M}$ aniline, (C) $1 \mathrm{~N} \mathrm{H}_{2} \mathrm{SO}_{4}+0.3 \mathrm{M}$ oxalic acid, (D) $1 \mathrm{~N} \mathrm{H}_{2} \mathrm{SO}_{4}+0.3 \mathrm{M}$ oxalic acid $+0.1 \mathrm{M}$ aniline.

\section{CONCLUSIONS}

(1) There has been a reversible reaction on $\mathrm{Al}$ in oxalic acid solutions. There has been also an irreversible reaction on Pt electrode.

(2) The addition of oxalic acid into $\mathrm{H}_{2} \mathrm{SO}_{4}$ solution has supported the formation of passiveness on electrode surface.

(3) The polymer film formed on the electrode surface has grown regularly and PANI has catalyzed this process.

(4) Aniline has been oxidized on Pt surface in lower currents.

(5) The fact that Al surface has been closed at the first cyclic in the solution composed of aniline shows that there has been the formation of oxide on $\mathrm{Al}$ surface. This oxide layer protects $\mathrm{Al}$ from corrosion. 
(6) Al and Pt electrode shows the character of passiveness in oxalic acid solution. There has been no passiveness range in $\mathrm{H}_{2} \mathrm{SO}_{4}$ solution.

(7) The fact that the anodic potentials has shifted to positive value as a result of the addition of aniline onto $\mathrm{H}_{2} \mathrm{SO}_{4}$ and oxalic acid solution shows that the metal anodic protection potentials.

(8) The fact that there has been oxalic acid in medium, polymer formation reaction has been accelerated.

\section{ACKNOWLEDGMENTS}

The author acknowledge the financial support of TUBITAK (Project no. TBAG-AY/412 (105T014)).

\section{REFERENCES}

1. Conroy, K.G. and Breslin, C.B., Electrochim. Acta., 2003, vol. 48, p. 721.

2. Gupta, R.K. and Singh, R.A., Mat. Chem. Phys., 2004, vol. 86, p. 279.

3. Abalyaeva, V.V. and Efimov, O.N., Polym. Adv. Technol., 1997, vol. 8, p. 517.

4. Racicot, R.J., Clark, R.L., Liu, H.B., et al., Mat. Res. Soc. Symp. Proc., 1996, vol. 413, p. 529.
5. Epstein, A.J., Smallfield, J.A.O., Guan, Fahlman, H.M., Synth. Met., 1999, vol. 102, p. 1374.

6. Racicot, R.J., Brown, R.L., and Yang, S.C., Synth. Met., 1997, vol. 85, p. 1263.

7. Choi, S.J. and Park, S.M., Electrochem. Soc., 2002, vol. 149 (E26-E34), p. 149.

8. Ryu, K.S., Kim, K.M., Park N.G., et al., Synthetic. Metals, 2001, vol. 119, p. 355.

9. Moraes, S., Hurtae-Vilca, D., and Motheo, A.J., Progress Org. Coatings, 2003, vol. 48, p. 28.

10. Eftekhari, A., Synthetic Metals, 2002, vol. 125, p. 295.

11. Pournaghi-azar, M.H. and Habibi, B., Electrochim. Acta, 2007, vol. 52, p. 4222.

12. Martyak, N.M., Mcandrewa, P., Mccaskie, J.E., and Dijon, J., Progress Org. Coatings. 2002, vol. 45, p. 23.

13. Carmel, B.B., Fenelon A.M., and Kenneth, G.C., Mat. Design., 2005, vol. 26, p. 233.

14. Karakisla, M., Electrochemical Polymerization of Aniline of a pt Electrodes with Coated Polymer, Ankara University, 1998, p. 100.

15. Camalet, J.L., Lacroix, J.C., Nguyen, T.D., et al., J. Electroanal. Chem., 2000, vol. 485, p. 13.

16. Lawrence, T.T., Sein, J., Wie, Y., and Jansen, S.A., Synthetic Metals, 2004, vol. 143, p. 1.

17. Lacroix, J.C., Camalet, J.L., Aeiyach, S., et al., J. Electroanal. Chem., 2000, vol. 481, p. 76.

18. Cecchetto, L., Delabouglise, D., and Petit, J.P., Electrochim. Acta, 2007, vol. 52, p. 3485.

SPELL: 1. voltammograms, 2. bidistilled 